\title{
Recurrent Colorectal Carcinoma
}

National Cancer Institute

\section{Source}

National Cancer Institute. Recurrent Colorectal Carcinoma. NCI Thesaurus. Code C8625.

The reemergence of colorectal carcinoma after a period of remission. 